\title{
ERRATUM
}

\section{The essential role of TNIK gene amplification in gastric cancer growth}

D-H Yu, X Zhang, H Wang, L Zhang, H Chen, M Hu, Z Dong, G Zhu, Z Qian, J Fan, X Su, Y Xu, L Zheng,

$\mathrm{H}$ Dong, $X$ Yin, Q Ji and J Ji

Oncogenesis (2014) 3, e93; doi:10.1038/oncsis.2014.9; published online 17 March 2014

Correction to: Oncogenesis (2014) 2, e89; doi:10.1038/ oncsis.2014.2; published online 24 February 2014

Owing to a typesetting error, the article citation was published incorrectly. It should read: Citation: Oncogenesis (2014) 3, e89; doi:10.1038/oncsis.2014.2

The original article has been corrected. 